En nu online ... 
Sibrenne Wagenaar

Joitske Hulsebosch

\section{En nu online ...}

Sociale media voor professionals, organisaties en trainers

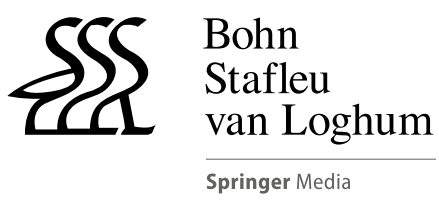




\section{ISBN 978-90-313-9745-7}

(c) Bohn Stafleu van Loghum, onderdeel van Springer Media 2013

Alle rechten voorbehouden. Niets uit deze uitgave mag worden verveelvoudigd, opgeslagen in een geautomatiseerd gegevensbestand, of openbaar gemaakt, in enige vorm of op enige wijze, hetzij elektronisch, mechanisch, door fotokopieën of opnamen, hetzij op enige andere manier, zonder voorafgaande schriftelijke toestemming van de uitgever.

Voor zover het maken van kopieën uit deze uitgave is toegestaan op grond van artikel 16b Auteurswet $j^{\circ}$ het Besluit van 20 juni 1974, Stb. 351, zoals gewijzigd bij het Besluit van 23 augustus 1985, Stb. 471 en artikel 17 Auteurswet, dient men de daarvoor wettelijk verschuldigde vergoedingen te voldoen aan de Stichting Reprorecht (Postbus 3060, 2130 KB Hoofddorp). Voor het overnemen van (een) gedeelte(n) uit deze uitgave in bloemlezingen, readers en andere compilatiewerken (artikel 16 Auteurswet) dient men zich tot de uitgever te wenden.

Samensteller(s) en uitgever zijn zich volledig bewust van hun taak een betrouwbare uitgave te verzorgen. Niettemin kunnen zij geen aansprakelijkheid aanvaarden voor drukfouten en andere onjuistheden die eventueel in deze uitgave voorkomen.

NUR 807

Serie: HRD-fonds

Eindredactie: Olga Koppenhagen, Voorburg

Ontwerp omslag: hAAi ontwerpbureau, Rotterdam

Ontwerp binnenwerk: Studio Bassa, Culemborg

Automatische opmaak: Crest Premedia Solutions (P) Ltd, Pune, India

Springer Media BV

Het Spoor 2

Postbus 246

3990 GA Houten

www.springermedia.nl 


\section{Inhoud}

Introductie

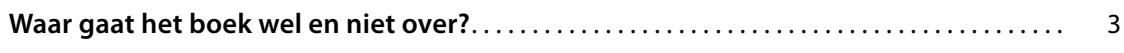

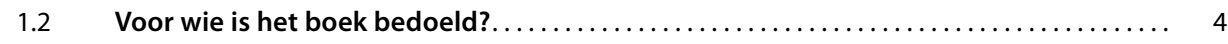

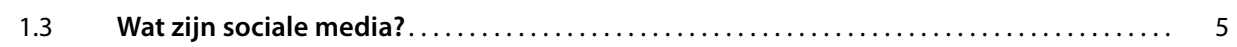

1.4 Sociale media en web2.0-tools $\ldots \ldots \ldots \ldots \ldots \ldots \ldots \ldots \ldots \ldots \ldots \ldots \ldots \ldots \ldots \ldots$

$1.5 \quad$ Kenmerkende socialemediatools $\ldots \ldots \ldots \ldots \ldots \ldots \ldots \ldots \ldots \ldots \ldots \ldots \ldots \ldots \ldots$

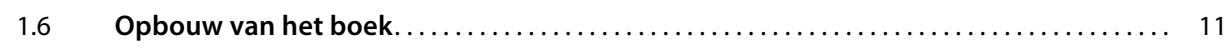

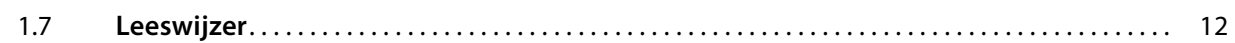

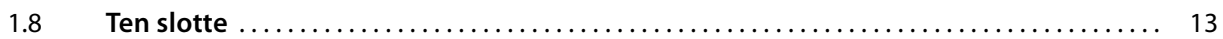

Deel 1 Aan de slag met sociale media als professional

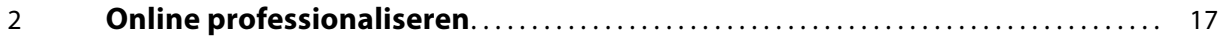

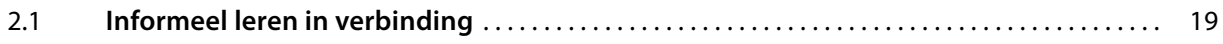

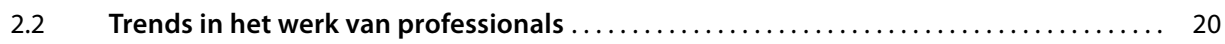

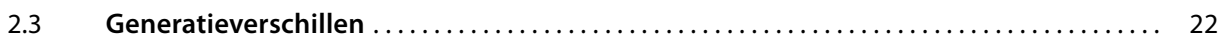

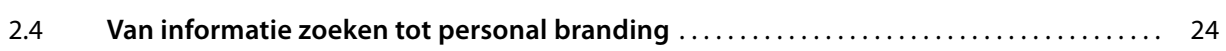

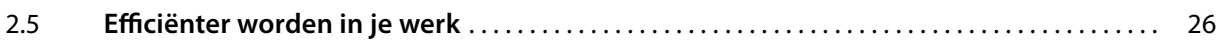

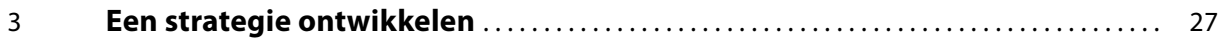

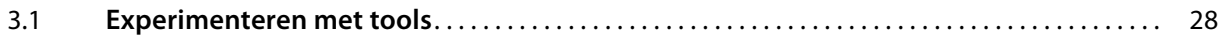

$3.2 \quad$ Het doel van werken met sociale media $\ldots \ldots \ldots \ldots \ldots \ldots \ldots \ldots \ldots \ldots \ldots \ldots \ldots \ldots \ldots$

Een socialemediastrategie in de praktijk $\ldots \ldots \ldots \ldots \ldots \ldots \ldots \ldots \ldots \ldots \ldots \ldots \ldots \ldots$

$3.4 \quad$ Nadelen en valkuilen van sociale media $\ldots \ldots \ldots \ldots \ldots \ldots \ldots \ldots \ldots \ldots \ldots \ldots \ldots \ldots, 42$

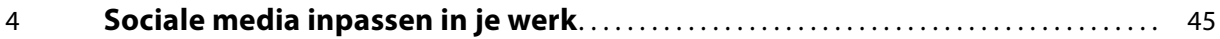

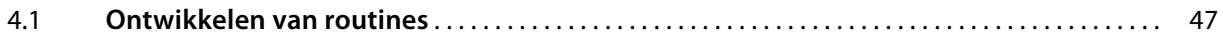

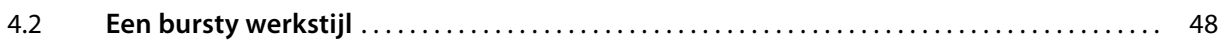

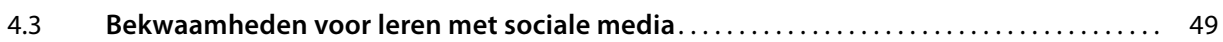

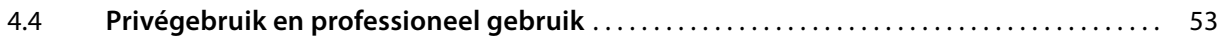

4.5 Afsluiting deel 1: Sociale media veranderen het leren en samenwerken

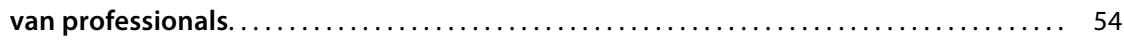

4.6 Tips \& Tools bij deel 1: Sociale media voor professionalisering $\ldots \ldots \ldots \ldots \ldots \ldots \ldots$

\section{Deel 2 Aan de slag met sociale media in teams en organisaties}

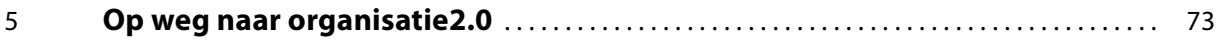

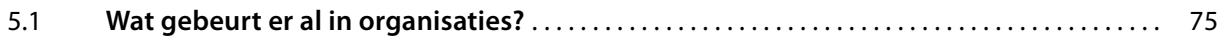

$5.2 \quad$ Functies van sociale media in een organisatie $\ldots \ldots \ldots \ldots \ldots \ldots \ldots \ldots \ldots \ldots \ldots \ldots$

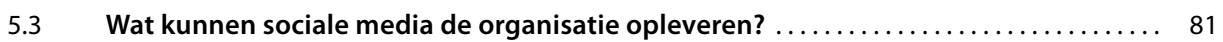

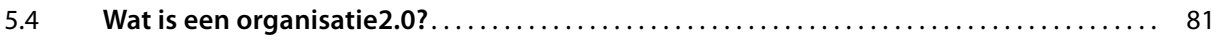

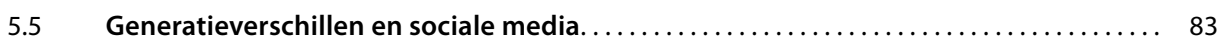




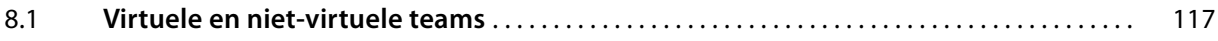

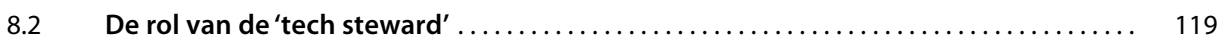

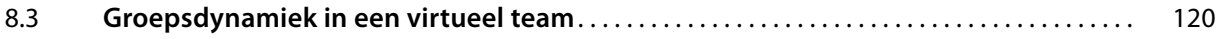

$8.4 \quad$ De keuze van webtools........................................... 122

$8.5 \quad$ Het introduceren van tools voor virtuele teams in 7 stappen $\ldots \ldots \ldots \ldots \ldots \ldots \ldots . \ldots \ldots$

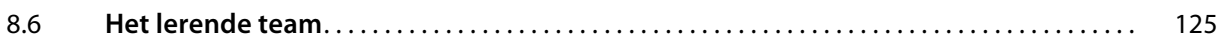

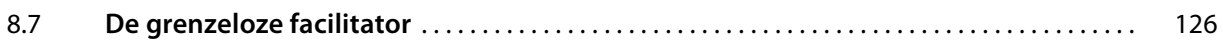

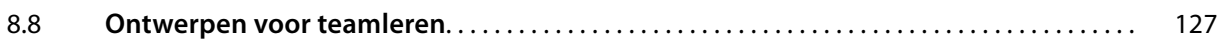

$8.9 \quad$ Specifieke interventies bij teams ................................... 129

8.10 Afsluiting deel 2: Sociale media beïnvloeden het leren en

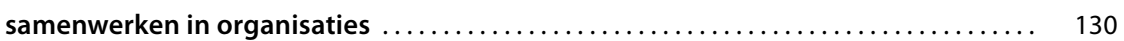

8.11 Tips \& Tools bij deel 2: Sociale media in organisaties...................... 132

\section{Deel 3 Aan de slag met online faciliteren}

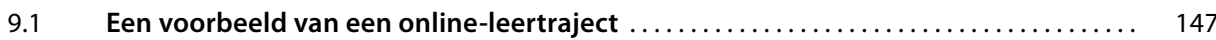

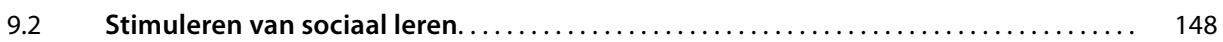

9.3 Sociale media als stimulans voor formeel en informeel leren $\ldots \ldots \ldots \ldots \ldots \ldots \ldots . \quad 150$

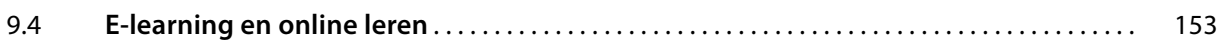

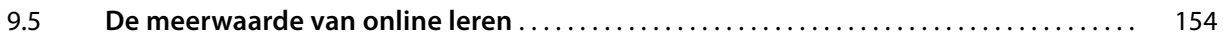

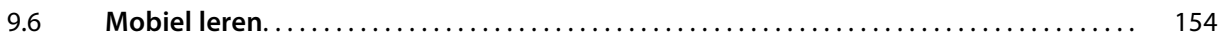

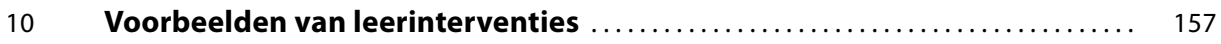

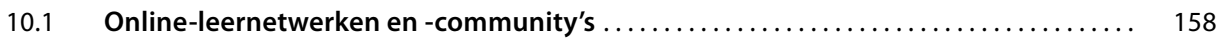

10.2 Het starten van een succesvolle community.......................... 160

10.3 Community's rond socialemediaservices: Twitter, Flickr en Blogging ........... 162

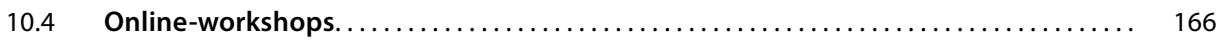

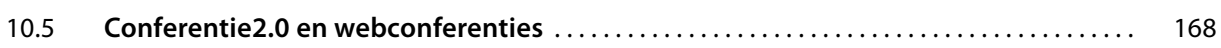

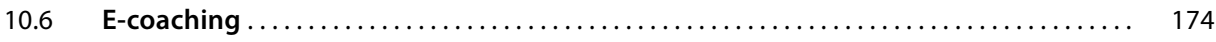

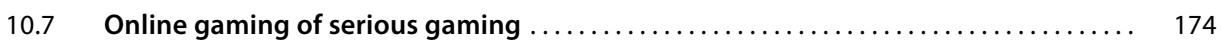




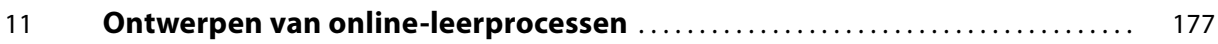

$11.1 \quad$ Ontwerpstappen voor het inrichten van online leren $\ldots \ldots \ldots \ldots \ldots \ldots \ldots \ldots \ldots \ldots$

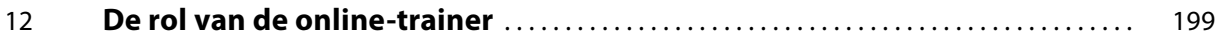

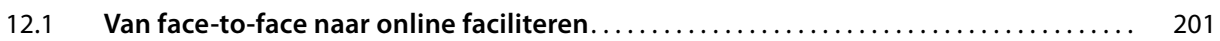

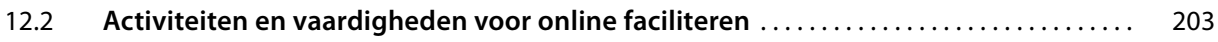

$12.3 \quad$ Verschillende rollen in een online-leeromgeving ......................... 205

12.4 Faciliteren van de overgangen face-to-face en online $\ldots \ldots \ldots \ldots \ldots \ldots \ldots \ldots \ldots \ldots$

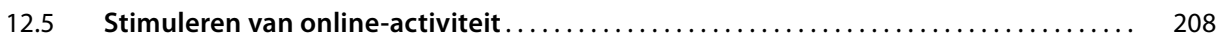

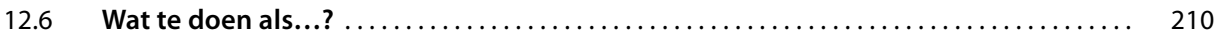

12.7 Afsluiting deel 3: Sociale media veranderen het faciliteren van leren ........... 213

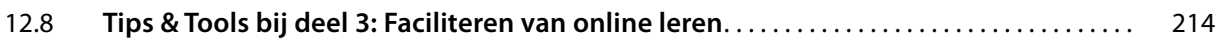

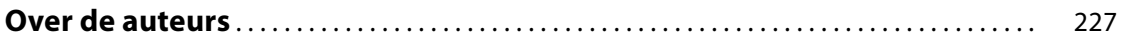

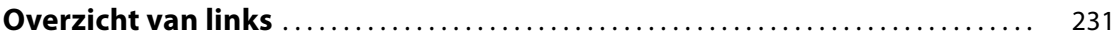




\section{Dankwoord}

Voor je ligt de tweede druk. In april 2007 zijn we begonnen met het schrijven van de eerste versie. Na een tijd met meer en minder intensieve schrijfperiodes, met boeiende gesprekken om praktijkverhalen te horen, met fasen van feedback verzamelen en met het ontwikkelen van nieuwe inzichten, mede door het lezen van een blogpost, lezen van een boek of het werken met professionals in onze praktijk, lag het boek er eind 2010. Het thema ontwikkelt zich voortdurend. In twee jaar tijd zijn er weer nieuwe inzichten bijgekomen en nieuwe tools met potentie voor leren en veranderen. Die hebben we in deze druk meegenomen. Tevens hebben we feedback van onze lezers ter harte genomen waardoor sommige delen zijn aangescherpt en voorbeelden toegevoegd.

Iedereen die een bijdrage heeft geleverd aan ons denken over het gebruik van sociale media in leerprocessen willen we heel hartelijk bedanken. Angelica Senders, Anita Smit, Anne-Marie Heemskerk, Catharinus Doornbos, Davied van Berlo, Godfried Knipscheer, Ina Nieborg, Jan-Jaap in de Maur, John Smith, Josien Kapma, Maarten Boers, Martin Kloos, Menno Lanting, Nancy White, Rob Coers, Rob Oele, Simon Koolwijk: dank jullie wel voor het met ons delen van jullie praktijkervaringen.

Elmine Wijnia, Josien Kapma, Laurent Umans, Maaike Smit, Ria van Dinteren, Russell Kerkhoven en Simon Koolwijk: jullie hebben onze eerste opzetten van dit boek gelezen en met jullie waardevolle feedback hebben jullie ons nieuwe energie en richting gegeven. We hebben dat heel erg gewaardeerd! En Ans Grotendorst, jou willen we graag in het bijzonder bedanken voor je meedenken vanaf het begin en de zeer zorgvuldige feedback die je hebt gegeven gedurende ons schrijfproces. Je geloof in de waarde van sociale media voor leerprocessen en de manier waarop wij dit hebben beschreven heeft ons heel veel goed gedaan en heeft zeker bijgedragen aan het uiteindelijke resultaat zoals dat er nu ligt.

Als laatste willen we ons online-netwerk bedanken, alle mensen die we volgen via RSS, Twitter en blogs of tegenkomen in online-community's, voor het delen van blogverhalen en tips via Twitter. Veel van wat er in dit boek staat hebben we via onze onlinenetwerken en -community's geleerd!

Sibrenne Wagenaar en Joitske Hulsebosch

Den Haag, mei 2012

\section{Hoe kun je ons inmiddels online volgen?}

Door de twitternaam @en_nu_online te volgen, ontvang je elke dag een tip over het gebruik van sociale media bij leren en veranderen ( $\downarrow$ http://twitter.com/en_nu_online).

Elke maand versturen we een e-nieuwsbrief, waar je je voor kunt aanmelden: - http://bit.ly/xgcMuU. 


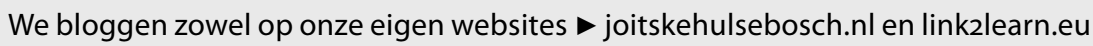
als op de site En nu online: $>$ http://www.ennuonline.com.

En wellicht wil je na dit boek nog meer lezen? Dan is er het boek 'Omdat het werkt!' verschenen, met 11 praktijkcasussen over het gebruik van sociale media bij leren en veranderen. Dit boek kun je hier gratis downloaden: http://losmakers.nl/download/. 


\section{Begrippenlijst}

Account Een registratie waardoor de gebruiker met een gebruikersnaam en wachtwoord toegang krijgt tot een bepaalde website of software.

Advanced search Een zoekfunctie waarmee via specifieke velden gezocht kan worden in de beschikbare informatie op een website.

Asynchrone tools Middelen waarmee je kunt communiceren zonder dat je tegelijk online hoeft te zijn; mensen reageren op verschillende tijdstippen.

Back-up Een reservekopie van een bestand, programma of software voor het geval dat de originelen verloren gaan.

Blogging tools Middelen waarmee je een online-dagboek kunt bijhouden. Het laatste bericht komt steeds bovenaan te staan.

Bloglines Een RSS-lezer speciaal ontwikkeld voor het lezen van blogs.

Breedband Een hogesnelheidinternettoegang (via ADSL of kabel).

Browser Een programma om op internet sites te kunnen bekijken. Voorbeelden zijn Internet Explorer van Microsoft en Firefox als open source-browser.

Bursty werkstijl Een werkstijl die gekenmerkt wordt door periodes van mindere en periodes van intensieve activiteit.

Buzz (op Hyves) Een functie op Hyves waar je onder andere de laatste reacties en nieuwe hyves van vrienden vindt.

Chattools Middelen voor interactieve communicatie door middel van tekstberichten (en emoticons). Wat de ene persoon intikt, verschijnt ongeveer gelijktijdig bij de andere op het beeldscherm en omgekeerd. Voorbeelden zijn MSN, Yahoo Messenger en Google Talk.

Cloud computing Gebruik van software via internet in plaats van software op de eigen computer of server. Een organisatie kan de software 'huren', waarbij het softwarepakket centraal op een server staat.

Critical friend Een systematische vorm van collegiale visitatie, die bestaat uit een training, een onderzoek en een presentatie. De methode is ontworpen door John Mcbeth.

Crowdsourcen Een manier van werken waarbij organisaties of personen gebruikmaken van een grote groep niet vooraf gespecificeerde individuen (professionals, vrijwilligers, geïnteresseerden) voor innovatie, beleidsvorming en onderzoek.

Directory Een gerubriceerd overzicht van websites, al dan niet voorzien van een uitgebreidere omschrijving.

Discussieforum Een online-discussiegroep waar mensen met een gemeenschappelijke interesse informatie, meningen en standpunten kunnen uitwisselen.

Distant closeness Een term die aangeeft dat sociale media nieuwe communicatiemiddelen zijn waarbij zonder direct contact mensen op de hoogte kunnen blijven van elkaars leven en welzijn.

E-collaboration Een samenwerking tussen mensen waarbij gebruik wordt gemaakt van elektronische middelen zoals de computer of mobiele telefoons.

Elevator pitch Een presentatiewijze van een idee voor een product, service of project. De naam geeft de tijdsduur weer waarin een lift van de onderste naar de bovenste verdieping gaat, in ongeveer 30 seconden of omgerekend rond de 100 woorden.

Eerste ring (op LinkedIn) De contacten waarmee een connectie is aangegaan. De contacten hebben elkaar toegevoegd als connectie.

Face-to-face Communicatie die tussen mensen plaatsvindt terwijl ze zich op dezelfde fysieke locatie bevinden. 
Firewall Programmatuur die zorgt voor een scheiding tussen een lokaal netwerk ('intranet') en het internet. Een firewall moet het kraken van computers tegengaan.

Formeel leren Alle vormen van leren binnen een gestructureerde leercontext, bijvoorbeeld op school of in een training.

Geek Engelse benaming voor iemand die gek is op technologie en/of computers.

Groepsdynamiek De bepalende factoren van het interactiegedrag van personen als leden van een groep.

Hashtag Een afgesproken kernwoord of afkorting die toegevoegd wordt aan berichtjes op Twitter waardoor mensen berichtjes over dit onderwerp kunnen vinden en erop kunnen reageren. Een hashtag begint met het \#-tekentje (bijv. \#kmers).

Hosten Het bedrijf dat 'host' zorgt ervoor dat de website van de aanbesteder beschikbaar is.

iGoogle Een gratis dienst van Google, een RSS-lezer die bedoeld is als online-startpagina van waaruit je het internet opgaat. Door RSS-feeds aan de pagina toe te voegen heb je een gepersonaliseerde startpagina met de nieuwste berichten van favoriete websites.

Informatieoverload Het probleem dat mensen moeite hebben om iets te begrijpen en een beslissing te nemen door een teveel aan informatie.

Informeel leren Het leren dat zich, min of meer spontaan, voordoet in een context die niet expliciet voor leren georganiseerd is, bijvoorbeeld: leren koken door het helpen in de keuken.

Instant messaging Systeem om te chatten op internet, zie ook'chattools'.

Interface Het raakvlak tussen mens en computer (de gebruikersinterface) of de koppeling tussen componenten (zowel software als hardware) in computersystemen.

Lifeblogger Een persoon die in een weblog zijn leven, of een deel van zijn leven, beschrijft.

Linkblogger Een persoon die in een weblog vooral links naar andere bronnen beschrijft.

Microblogging-tools Tools waarbij de gebruikers veel kortere tekstberichten en/of kleinere mediabestanden plaatsen dan op een weblog (bij Twitter maximaal 140 tekens). Vaak wordt microblogging gebruikt om geïnteresseerden op de hoogte te houden van de eigen activiteiten.

Mobiel internet Verwijst naar het gebruik van het internet via een draadloos netwerk met behulp van een mobiel apparaat, zoals een daarvoor geschikte mobiele telefoon, Personal Digital Assistant, smartphone, pocket-pc, handheld pc of laptop.

Multitasken Meerdere taken tegelijk uitvoeren.

(het) Nieuwe werken Plaats- en tijdonafhankelijk uitvoeren van kantoorwerkzaamheden. Hierbij wordt gebruikgemaakt van mobiele technologie zoals laptops, smartphones en socialemediatools.

Offline Engels voor het niet verbonden zijn met het internet; de tegenhanger van online (verbonden zijn met het internet).

Open source De praktijk die vrije toegang geeft tot de bronmaterialen (de source) van het product, zodat iedereen hiermee verder kan gaan ontwikkelen.

Online-community Een online-ontmoetingsplaats waar mensen zich verzamelen, elkaar opzoeken en met elkaar in contact treden op basis van een gemeenschappelijke interesse.

Online-community of practice Mensen die een professionele praktijk delen en door online-interactie leren hoe ze hier beter in kunnen worden.

Online-discussie Een inhoudelijke uitwisseling via een online-forum die het mogelijk maakt om berichtjes te plaatsen in reactie op andere berichten.

Online-forum Elektronische discussiegroep waar mensen met een gemeenschappelijke interesse informatie, meningen en standpunten kunnen uitwisselen.

Online ideagoras Een online-marktplaats voor ideeën en uitvindingen. 
Online survey Een enquête die online ingevuld kan worden.

Personal branding Het ontdekken, zichtbaar maken en versterken van je talenten en onderscheidende waarde om meer energie, plezier en succes in je werk te realiseren.

Podcast Een audioprogramma dat via internet beschikbaar wordt gesteld aan mensen met een iPod of andere digitale mp3-speler.

Pop-upnotificatie Een bericht dat in een nieuw scherm(pje) wordt geopend.

Realtime communicatie Directe communicatie. Hierbij vindt het uitwisselen van tekst, geluid en/of beeld zonder wachttijden plaats.

RSS-feed Een technisch hulpmiddel waarmee je je op de nieuwe berichten van een website kunt abonneren.

RSS-lezer Een online-nieuwslezer die nieuwe informatie van de RSS-feeds waarop je geabonneerd bent laat zien (bijv. Pageflakes, Googlereader of Netvibes).

Serious gaming Games of simulaties die door bedrijven worden ingezet om serieuze problemen op te lossen.

Sociaal-constructivistische leertheorie Theorie die ervan uitgaat dat mensen zelf betekenis verlenen aan hun omgeving en dat sociale processen hierbij een prominente rol spelen. Kennis wordt door ieder mens op een eigen wijze geconstrueerd, waarbij men sterk wordt beïnvloed door de reacties en opvattingen in de sociale omgeving.

Social bookmarking Een manier om via internet bladwijzers ofwel favorieten te delen, waarbij deze openbaar toegankelijk zijn.

Software Computerprogrammatuur die instructies aan het computersysteem bevat en het mogelijk maakt dat de computerapparatuur taken uitvoert.

Status update Kort berichtje waarin je laat weten waar je bent of wat je aan het doen bent. Status updates is een functionaliteit op verschillende platforms zoals Linkedln, Skype en Facebook.

Synchrone communicatie Middelen waarmee je kunt communiceren terwijl je tegelijk online bent, met andere woorden: je krijgt in realtime reactie.

Tag Een zelfgekozen trefwoord (label) dat door de gebruiker gekoppeld wordt aan een website (tekst, video, audio).

Technology steward lemand met genoeg ervaring in een community om de behoeften aan technologische ondersteuning te begrijpen en genoeg ervaring met technologie om een rol te kunnen spelen bij het helpen vervullen van deze behoeften.

Teleconferentietools Middelen voor een gesprek (vergadering) tussen mensen op afstand.

Tribe Engelse term voor een gemeenschap. Een tribe kan open, gesloten of geheim zijn.

Tweede ring (op LinkedIn) De contacten van de eerste ring-contacten. Heb je 10 contacten en hebben deze ieder weer 10 contacten, dan bestaat de tweede ring uit 100 contacten.

Tweetdeck Een applicatie waarmee gebruikers kunnen communiceren via hun accounts op Twitter, Facebook, LinkedIn en MySpace (tweetdeck.com).

Wifi De afkorting van Wireless Fidelity, een techniek waarmee een computernetwerk met behulp van een radiozender en radio-ontvanger draadloos kan worden opgebouwd.

Webdesigner lemand die zich bezighoudt met het maken en vormgeven van websites op het internet.

Webredacteur lemand die teksten voor internet en intranet schrijft, herschrijft en redigeert.

Weblog Een website waarop een dagboek wordt bijgehouden. Er verschijnen regelmatig nieuwe bijdragen. De informatie wordt in omgekeerde chronologische volgorde (het nieuwste bericht verschijnt als eerste) weergegeven. 
Webtool Een online-gereedschap met een bepaalde functie. Flickr is bijvoorbeeld een webtool waarbij je foto's kunt uploaden, bewaren en delen, Skype is een webtool voor gesprekken, teleconferenties en instant messaging.

Widget Een kleine applicatie die op een website gehost wordt, maar op andere websites gebruikt kan worden. Een widget is te kopiëren naar een andere site door middel van een code.

Wiki Een applicatie of (web)toepassing waarmee webdocumenten gezamenlijk kunnen worden bewerkt.

Wikinomics Een verbinding van de woorden 'wiki' en 'economics'. Het omvat een nieuwe manier van organiseren en werken. Kerngedachte bij wikinomics is dat de omgeving van een onderneming veel meer weet en kan dan die onderneming zelf. Daar kan de onderneming gebruik van maken.

Workplace internet leisure browsing De praktijk van het op het werk voor je plezier op internet surfen. 